\title{
Dinâmica dos vencimentos e da remuneração docente nas redes estaduais no contexto do Fundeb e do PSPN ${ }^{1}$
}

\author{
Dynamics of teacher salaries on state schools in the context of Fundeb and \\ PSPN \\ Dinámica de los vencimientos y la remuneración docente en las redes \\ estaduales en el contexto del Fundeb y del PSPN
}

\section{RUBENS BARBOSA DE CAMARGO THIAGO ALVES MARIA DA GRAÇA BOLLMANN}

\begin{abstract}
Resumo: O objetivo desse artigo é analisar a dinâmica dos vencimentos e da remuneração de professores da Educação Básica de 10 redes estaduais no período de 2006 a 2014. As fontes de dados utilizadas foram as tabelas de vencimentos e os microdados da RAIS. Os dados mostraram evidências de que no período analisado, coincidente com a transição do Fundef para o Fundeb e do início da vigência do PSPN, houve crescimento real na remuneração média dos professores das redes analisadas, apesar de bastante variável entre as redes (de 10\% a 143\%). Verificou-se que há grande heterogeneidade entre as redes e que os possíveis impactos do PSPN e do Fundeb têm singularidades em cada uma.
\end{abstract}

Palavras-chave: Política Educacional; Remuneração Docente; Fundeb; PSPN; Educação Básica.

\begin{abstract}
The article aims to analyze the dynamics of the teacher salaries in basic education from 10 state schools from 2006 to 2014. The data sources used were the salary tables and the microdata of the RAIS. The results showed evidence that in the analyzed period, coinciding with the transition from Fundef to Fundeb and the beginning of the PSPN, there was a real increase in the average teacher salaries, although it was quite variable between state schools (from $10 \%$ to $143 \%$ ). It was verified that there is great heterogeneity between the state schools and that the possible impacts of PSPN and Fundeb have singularities in each one.
\end{abstract}

Keywords: teacher salaries; educational policy; Fundeb; PSPN; basic education.

\footnotetext{
$1 \quad$ Este artigo apresenta parte dos resultados da pesquisa nacional "Remuneração de professores de escola pública de educação básica no contexto do Fundeb e do PSPN”, financiada segundo o Edital: 049/2012 CAPES/ INEP/SECAD - Observatório da Educação (denominada como Pesquisa Nacional Observatório da Educação - PORD - http://observatorioderemuneracaodocente.fe.usp.br/), sob a Coordenação Nacional do Prof. Dr. Marcos Edgar Bassi (UFPR/UFSC) (Coordenador Nacional), da Profa. Dra. Rosana Gemaque (UFPA) e da Profa. Dra. Maria Dilnéia Espíndola Fernandes (UFMS). A pesquisa foi realizada de 2013 a 2017 e contou com equipes de pesquisadores ligadas a universidades dos seguintes estados: Rio Grande do Sul (UFRGS), Santa Catarina (UFSC e Unisul), Paraná (UFPR), São Paulo (USP e UNIFESP), Minas Gerais (UEMG), Mato Grosso do Sul (UFMS), Mato Grosso (UNEMAT), Rio Grande do Norte (UFRN), Piauí (UFPI) e Pará (UFPA).
} 
Resumen: El propósito de este artículo es analizar la dinámica de vencimientos y de la remuneraciones de profesores de la educación básica de 10 redes estatales en el período 2006 a 2014. Las fuentes de datos utilizadas fueron las tablas de vencimientos y los microdatos de la RAIS. Los datos evedencian que en el periodo analizado, coincidiendo con la trasición de Fundef para el Fundeb y el comienzo de la PSPN, hubo un creciemiento real en la remuneración media de los profesores de las redes analizadas, aunque muy variable entre las redes (de $10 \%$ a $143 \%$ ). Se verificó que existe gran diversidad entre las redes y que los impactos posibles de PSPN y de Fundeb tienen singularidades en cada una.

Palabras clave: Política Educativa; Remuneración Docente; Fundeb; PSPN; Educación básica.

\section{INTRODUÇÃO}

O objetivo deste artigo é analisar a dinâmica dos vencimentos e da remuneração dos professores da Educação Básica de 10 redes estaduais (Pará, Piauí, Rio Grande do Norte, Mato Grosso, Mato Grosso do Sul, Minas Gerais, São Paulo, Paraná, Santa Catarina e Rio Grande do Sul) no período de 2006 a 2014. Duas fontes de dados foram utilizadas: as tabelas de vencimentos das redes estaduais coletadas via pesquisa documental; e os microdados da Relação Anual de Informações Sociais (RAIS) disponibilizados no sítio eletrônico do Ministério do Trabalho.

A escolha do recorte temporal (2006 a 2014) deve-se ao estabelecimento, em 2007, do Fundo de Manutenção e Desenvolvimento da Educação Básica e de Valorização dos Profissionais da Educação (Fundeb) criado pela Emenda Constitucional (EC) 53/2006 (BRASIL, 2006) e regulamentado pela Lei 11.494/2007 (BRASIL, 2007) e, também, à criação da lei do Piso Salarial Profissional Nacional (PSPN) para professores da Educação Básica no país - Lei 11.738/2008 (BRASIL, 2008). Vale frisar que o PSPN teve sua validade formalmente estabelecida somente em abril de 2011, após julgamento de sua constitucionalidade pelo Supremo Tribunal Federal (STF). Essa Lei estabeleceu que, a partir de 2010, “O piso salarial profissional nacional é o valor abaixo do qual a União, os estados, o Distrito Federal e os municípios não poderão fixar o vencimento inicial das Carreiras do magistério público da Educação Básica, para a jornada de, no máximo, 40 (quarenta) horas semanais" (\$1o do Art. $2^{\circ}$, BRASIL, 2008) (grifos nossos). Tal piso foi e é estabelecido pela União desde 2008 para docentes com formação de nível médio na modalidade Normal, guardando relação com o valor mínimo nacional de aluno ano do Fundeb, também estabelecido pela União.

É de amplo domínio nacional que, para se garantir uma educação pública de qualidade, há necessidade de que sejam asseguradas políticas de valorização para 
os profissionais do magistério público. A Constituição Federal de 1988 (CF/88) define em seu artigo 206, incisos V e VIII (BRASIL, 1988), os eixos da valorização profissional: planos de carreiras, ingresso exclusivamente através de concurso público (prova e títulos) e implantação de piso salarial profissional. Desde então, medidas legais foram tomadas na perspectiva de colocar em vigor as determinações constitucionais, mediante ordenamento jurídico nacional complementar, o qual, atualmente, legitima a implantação das políticas educacionais que visam à garantia da educação pública de qualidade para todos, entre elas: LDB, Fundef, Fundeb, Piso Salarial Profissional Nacional e Plano Nacional de Educação.

A literatura mais crítica sobre os fundos de manutenção, desde os primeiros balanços do Fundef (ARELARO, 1999; DAVIES, 1998; PINTO, 2000, entre outros), até os textos mais recentes que incluem o período de vigência do Fundeb (FARENZENA, 2006; BASSI, 2009; OLIVEIRA, 2007; PINTO, 2007; CASTRO, 2007 etc.), aponta para a possibilidade de diminuição da desigualdade mais significativa entre os municípios que estão nos territórios de abrangência de cada fundo estadual, embora não da mesma forma, quando se discutem e se avaliam as desigualdades regionais existentes no país. Entre os muitos dados da desigualdade educacional está a remuneração docente em cada estado e município do país.

No próprio mecanismo do Fundeb, houve tanto a manutenção de uma subvinculação de recursos para pagamento dos profissionais da educação (60\%, no mínimo) quanto a previsão de criação do PSPN, que veio a se tornar a Lei 11.738/2008 (BRASIL, 2008) com a perspectiva de que o pagamento de docentes em todo país pudesse ter um parâmetro mínimo, definido anualmente, pelo Ministério da Educação. E como seu valor está associado ao valor aluno ano do Fundeb, tal política de piso poderia ocasionar uma diminuição da grande desigualdade entre a remuneração docente entre os entes federativos (GOUVEIA; CRUZ; CAMARGO; OLIVEIRA, 2006), bem como a remuneração de outros profissionais com o mesmo nível de formação (JACOMINI; ALVES; CAMARGO, 2016). É nesse contexto que este artigo pretende analisar, como já mencionado, a dinâmica dos vencimentos e da remuneração dos professores da Educação Básica de 10 redes estaduais.

A partir dessa introdução, o artigo apresenta outras quatro seções. A primeira foi reservada aos procedimentos metodológicos. A segunda apresenta a dinâmica dos vencimentos e a terceira tratou da remuneração docente. A seção final foi endereçada às considerações finais. 


\section{PROCEDIMENTOS METODOLÓGICOS}

Para uma delimitação conceitual do objeto de estudo, é importante resgatar a definição de remuneração e de vencimento. O vencimento dos docentes da Educação Básica é um conceito fundamental para compreensão dos valores monetários a serem retribuídos a professoras e professores de redes públicas em contrapartida a uma jornada de trabalho fixada e que faz parte de uma estrutura de carreira estabelecida em legislação específica em cada ente federativo. Em geral, conceitualmente, a estrutura da carreira docente corresponde a uma tabela de posição de dupla entrada com valores crescentes onde pode ocorrer uma movimentação horizontal ou vertical do docente de acordo com critérios previstos em legislação (formação inicial, tempo, cursos de formação continuada etc.). A remuneração, por sua vez, é composta pela somatória do vencimento básico (principal item) com os diferentes itens que correspondem a vantagens fixas (por exemplo, os adicionais por tempo de serviço etc.) e vantagens variáveis (por exemplo, as gratificações de local de trabalho, entre outras) previstas em planos de cargos e carreira ou estatutos do magistério.

\section{PROCEDIMENTOS COM AS TABELAS DE VENCIMENTO}

Para o levantamento dos dados dos vencimentos, foi realizada uma pesquisa documental da legislação que estabeleceu os valores dos vencimentos para as jornadas padrão, que variaram de estado para estado, vigentes no período de 2006 a 2014. As pesquisas foram realizadas em Diários Oficiais de cada ente federativo estadual dos dez estados participantes e dispostas em referência organizada pela pesquisa nacional (PORD, 2013, mimeo).

Os valores dos vencimentos das redes estaduais, embora estabelecidos para as jornadas padrão, nesta pesquisa foram padronizados para uma jornada de trabalho docente de 40 horas semanais. Como nem todas as redes adotam jornadas de 40 horas, a padronização é necessária para permitir comparações entre as redes e com o PSPN. Além disso, para permitir a comparação do poder de compra dos vencimentos nos diferentes anos, todos os valores foram corrigidos do mês de outubro de cada ano para dezembro de 2014 pelo Índice Nacional de Preços ao Consumidor (INPC), divulgado pelo Instituto Brasileiro de Geografia e Estatística (IBGE). 


\section{PROCEDIMENTOS COM AS RAIS}

A RAIS é um levantamento anual realizado pelo Ministério do Trabalho desde 1975 cujo objetivo (dentre outros) é o provimento de dados para a elaboração de estatísticas do trabalho. Por força de lei, no Brasil, todos os empregadores (de estabelecimentos públicos ou privados; urbanos ou rurais) são obrigados a prestar informações sobre as características dos vínculos de emprego ativos ou inativos em 31/12 de cada ano. Para isso, o Ministério do Trabalho disponibiliza um sistema eletrônico no qual os dados devem ser informados. Todavia, apesar de mais de quatro décadas de levantamento anual, os microdados da RAIS, somente em 2012 passaram a ser disponibilizados com acesso aberto e pela internet ${ }^{2}$. Talvez essa seja a explicação para que haja pequeno número de pesquisas sobre salários docentes que utilizaram a RAIS (ver FERNANDES; GOUVEIA; BENINI, 2012; e INEP, 2017, por exemplo).

É importante ressaltar que a RAIS é uma fonte que contém a 'remuneração' dos trabalhadores (e não o vencimento, conforme definição apresentada). Para isso, nesse estudo, foi utilizada a variável "valor da remuneração média nominal" constante nos microdados. Desse modo, segundo a lista de itens de remuneração apresentada em MTb (2016, p.36), nos valores da referida variável estão contidos salários, vencimentos, vantagens, abonos, adicionais por tempo de serviço, remuneração do período de férias, suplementações, bonificações, gratificações, comissões etc. Corretamente, o $13^{\circ}$ salário não compõe essa variável. Porém, está contida a 'remuneração do período de férias' (referente a $1 / 3$ do salário base) e esse valor pode distorcer, para maior (em cerca de 2,78\%), a remuneração mensal típica dos professores. Em procedimento análogo ao realizado com os valores das tabelas de vencimento, nesse estudo foi utilizado o valor da "Remuneração média padronizada para jornada de $40 \mathrm{~h}$ semanais" (Valor calculado a partir do valor da remuneração média nominal dividido pela quantidade de horas contratadas e multiplicado por 40). Os valores também foram atualizados de dezembro de cada ano para dezembro/2014 pelo INPC/IBGE. Para evitar distorções da média, foram retirados os valores considerados atípicos (valores que estavam três desvios-padrão acima ou abaixo da média de cada rede de ensino analisada).

2 Atualmente, os microdados da RAIS, referente ao período de 1985 a 2016, estão disponíveis em ftp://ftp.mtps.gov.br/pdet/microdados/RAIS/. 
Além da "Remuneração média padronizada para jornada de 40h semanais", neste estudo foram utilizadas outras cinco variáveis geradas a partir das variáveis originais dos microdados: Professor da Educação Básica ${ }^{3}$; Dependência administrativa ${ }^{4}$, Jornada de trabalho, Nível de formação ${ }^{5}$, Tipo de vínculo de emprego ${ }^{6}$. Vale ressaltar que gerar variáveis transformadas envolve interpretações e escolhas. Isso se fez necessário porque a RAIS não é um levantamento específico da área de educação, como os realizados pelo INEP. As implicações disso são possíveis divergências entre estudos.

\section{ANÁLISE DAS TABELAS DE VENCIMENTO}

O gráfico 1 retrata a dinâmica existente sobre os valores dos vencimentos iniciais de docentes da amostra de 10 estados com formação superior em jornada de trabalho padronizada para 40 horas semanais. Há ainda a linha da média aritmética dos valores da amostra; a linha dos valores do PSPN, bem como as retas das tendências lineares da média (rosa) e do PSPN (preta) com as respectivas equações que as determinam.

3 Foram considerados professores da educação básica somente os vínculos de emprego que constavam as seguintes ocupações, de acordo com a Classificação Brasileira de Ocupações (CBO) edição 2002 [CBOOcupação2002]: 231105, 231110, 231205, 231210, 231305, 231310, 231315, 231320, 231325, 231330, 231335, 231340, 232105, 232110, 232115, 232120, 232125, 232130, 232135, 232140, 232145, 232150, 232155, $232160,232165,232170,331105,331205,331305,332105,332205,233110,233115,233120,233125,233130$, 233135, 239205, 239210, 239215, 239220, 239225, 239420.

4 A variável "Dependência Administrativa" foi gerada a partir da variável original "[NaturezaJurídica]" e contém as seguintes categorias analíticas (entre colchetes estão os códigos da variável original que foram agregados): 1 - Federal [1015, 1040, 1074, 1104, 1139, 1163]; 2 - Estadual [1023, 1058, 1082, 1112, 1147, 1171]; 3 - Municipal [1031, 1066, 1120, 1155, 1180]; e 4 - Pública [1201, 1210, 2011].

5 A variável "Nível de formação" foi gerada a partir da variável original "[Escolaridadeapós2005]" e contém as seguintes categorias analíticas (entre colchetes estão os códigos da variável original que foram agregados): 1 - Ensino Fundamental incompleto ou não estudou [1, 2, 3, 4]; 2 - Ensino Fundamental [5,6]; 3 Ensino Médio completo [7,8]; 4 - Ensino Superior completo [9]; 5 - Mestrado [10]; 6 - Doutorado [11].

6 A variável "Tipo de vínculo empregatício" foi gerada a partir da variável original "TipoVínculo" e contém as seguintes categorias analíticas (entre colchetes estão os códigos da variável original que foram agregados): 1 - Celetista [10, 15, 20, 25, 60, 65, 70, 75]; 2 - Estatutário (RJU) [30, 31]; 3 - Servidor não efetivo [35]; 4 - Temporário [50, 90, 95, 96, 97]; 5 - Aprendiz [55]; 6 - Sem vínculo [80]; 7 - Outros contratos [40]. 
Gráfico 1 - Vencimentos Iniciais, professores com formação em nível superior, redes estaduais, 2006 a 2014 (valores em $\mathbf{R} \$$ padronizados para uma jornada semanal de $40 \mathrm{~h}$ e corrigidos para dez/2014)

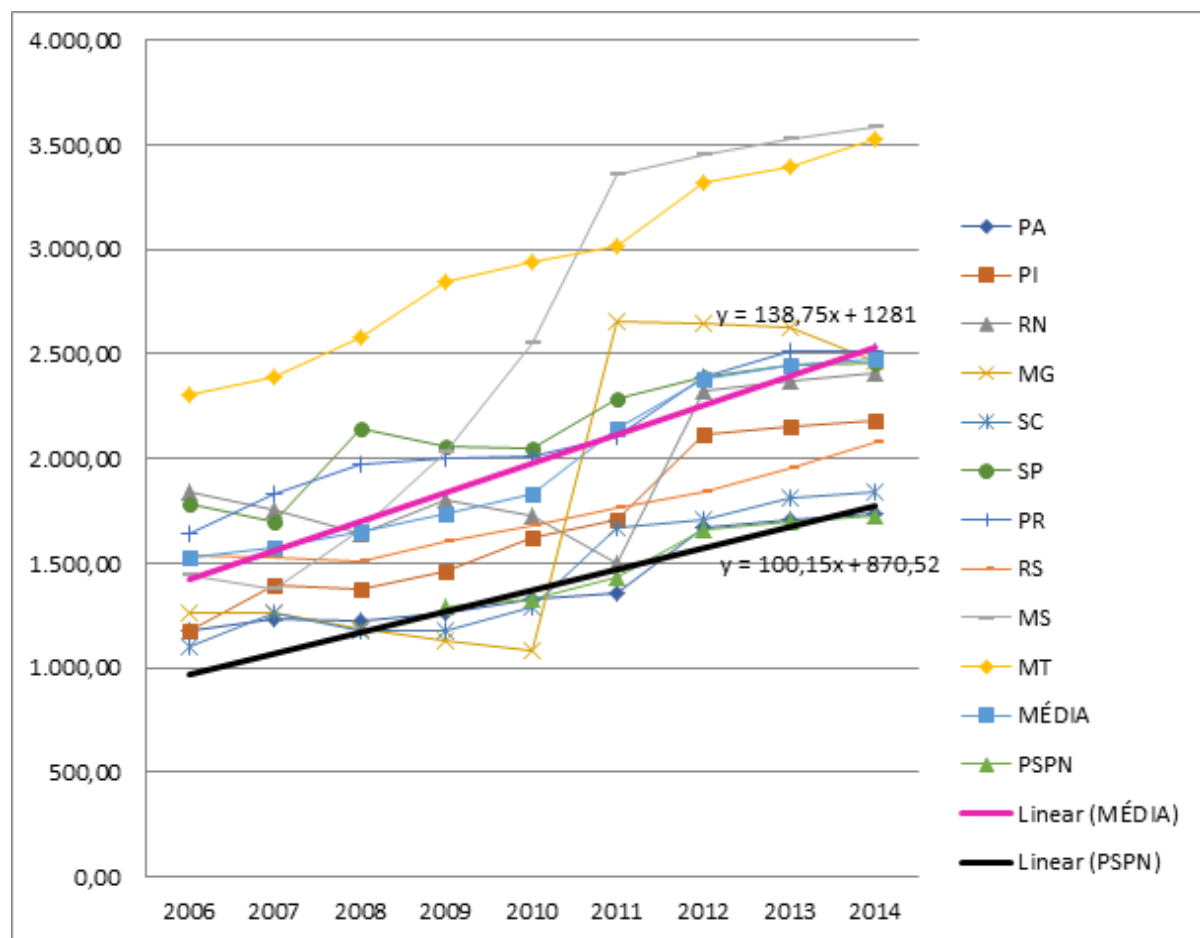

Fonte: Elaboração dos autores a partir das tabelas de vencimentos coletadas pela PORD.

Em 2006, com exceção de MT, que se destaca com valor de $\mathrm{R} \$ 2.301,73$ no primeiro ano da série, o menor valor corrigido se encontra em SC com R\$ $1.100,55$ e o maior valor encontra-se no $\mathrm{RN}$ com $\mathrm{R} \$ 1.841,43$, o que permite calcular a diferença em $\mathrm{R} \$ 740,88$ ( $\mathrm{R} \$ 1.201,18$ se calcularmos em relação ao MT). Já em 2014, há duas exceções para o "comportamento de grupo": MS (R\$ $3.588,85$, o maior valor) e MT (R \$ 3.532,13). Enquanto os demais estados estão entre os valores do PA $(\mathrm{R} \$ 1.731,97)$, o menor e o do PR ( $\$$ 2.511,33), o maior; com uma diferença entre estes de $\mathrm{R} \$ 779,36$, bem próxima à diferença detectada em 2006.

No período de 2006 a 2014, a maior variação absoluta dos vencimentos iniciais para professoras e professores com licenciatura ocorreu em MS e foi de $\mathrm{R} \$ 2.148,68$, o que correspondeu também à maior variação relativa $(149,2 \%)$. A menor variação absoluta aconteceu no RS e foi de R $\$ 540,17$, enquanto que a menor variação relativa foi no $\mathrm{RN}$ : apenas $31,0 \%$. 
O comportamento da média aritmética dos vencimentos dos licenciados variou de $R$ \$1.526,80 em 2006 para $R \$ 2.480,20$ no ano de 2014 (variação absoluta de $\mathrm{R} \$ 953,40$ e relativa de 62,4\%). Essa variação foi maior do que as do PSPN, que corresponderam a $\mathrm{R} \$ 434,88$ e 33,7\%, respectivamente, mas que se refere ao piso dos docentes com formação de nível médio. Isso pode significar que houve uma valorização real no período, com aumento claramente detectado, seja porque o Fundeb trouxe um pouco mais de recursos para as redes (e é importante destacar que todas as redes estaduais "perdem" recursos para os fundos no âmbito de cada estado), seja porque os estados ao buscar cumprir a lei do PSPN (ao menos para os docentes com formação de nível médio, incidiram também sobre os vencimentos dos demais docentes, com formações distintas), para os licenciados estabeleceram que na média ele foi pouco maior que o praticado no PSPN (42,7\% e 33,7\%, no período de 2009 a 2014).

Outras informações destacam-se no gráfico 1. A primeira delas diz respeito ao comportamento dos vencimentos iniciais para docentes com licenciatura em relação ao valor do PSPN (R \$ 1.723,46, corrigido). Embora o valor do piso seja para professoras e professores com formação de nível médio, não há estados em que os valores pagos na forma de vencimentos para docentes com formação em nível superior são menores do que o PSPN, mas o PA (R\$ $1.731,97)$ se aproxima muito. O que corrobora as denúncias feitas pela CNTE de que houve um "achatamento" das carreiras, pois antes as diferenças entre os níveis de formação eram maiores.

A outra informação diz respeito às retas que simbolizam a tendência linear da média aritmética simples (linha rosa) dos vencimentos iniciais de docentes com licenciatura e a do PSPN (linha preta), pois elas estão se distanciando levemente uma da outra. As equações são: $y$ (média) $=138,75 x+1281$ para a linha de tendência da média e y $($ PSPN $)=100,15 x+870,52$ para a linha de tendência do PSPN. Isso pode revelar que a média dos valores dos vencimentos iniciais dos docentes com licenciatura da amostra aumenta levemente em relação ao crescimento do valor do PSPN. Se levarmos em conta que os valores dos vencimentos das redes estaduais são maiores que as municipais e que a amostra pode representar todos os estados do país, depreende-se que o aumento do valor anual do PSPN interfere leve e positivamente nos valores dos vencimentos dos professores com Licenciatura Plena, mas que, ainda assim, estão longe de configurarem vencimentos dignos aos docentes da Educação Básica. 


\section{VENCIMENTOS FINAIS DOS DOCENTES COM FORMAÇÃO EM NÍVEL SUPERIOR}

O Gráfico 2 apresenta a dinâmica dos vencimentos finais (valores correspondentes à última posição possível de se atingir na carreira docente) em cada rede estadual no período de 2006 a 2014, bem como apresenta as linhas com os valores da média aritmética da amostra e do PSPN. Além disso, também mostra as linhas de tendências da média (linha rosa) e do PSPN (linha preta) e suas respectivas equações.

\section{Gráfico 2 - Vencimentos no final da carreira, professores com formação em nível superior, redes estaduais, 2006 a 2014 (valores em R\$ padronizados uma jornada semanal de 40h e corrigidos para dez/2014)}

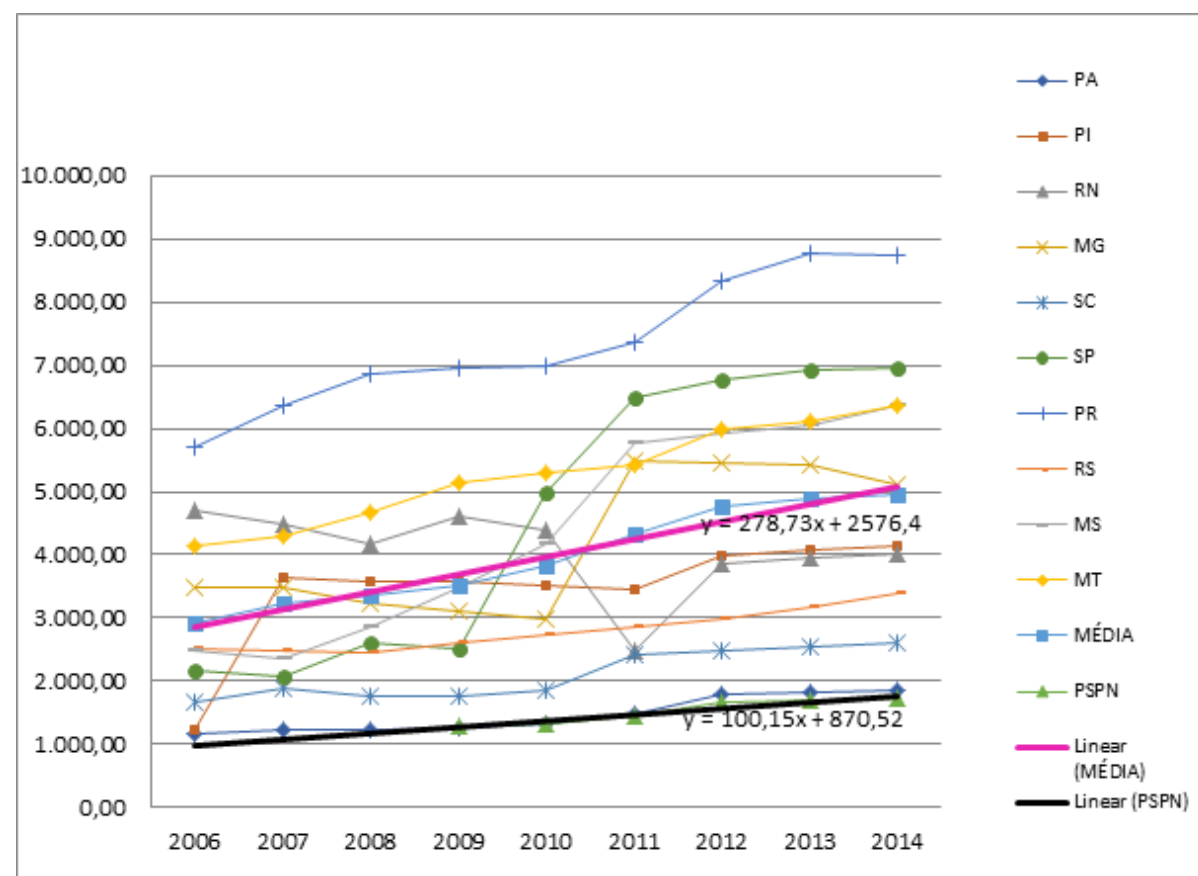

Fonte: Elaboração dos autores a partir das tabelas de vencimentos coletadas pela PORD.

No gráfico 2, é possível também perceber um sentido geral de ascensão dos valores dos vencimentos finais das carreiras das redes estaduais, no período de 2006 a 2014. No entanto, de modo muito mais disperso do que no gráfico anterior. Embora se tenha a composição de um grupo de estados um pouco mais concentrado, claramente o PA e o PR se destacam deste grupo (quase sempre com 
valores crescentes, e voltamos a destacar que uma jornada de 40h pode não existir nos diferentes estados). Nota-se que em alguns estados do grupo houve, inclusive, decréscimo, como foi o caso do Rio Grande do Norte e de Minas Gerais.

Em 2006, o menor valor encontrado correspondeu ao vencimento final do PA (R\$ 1.234,83) e o maior valor do vencimento final ocorreu no PR (R\$ $5.707,15)$, estabelecendo uma diferença de $\mathrm{R} \$ 4.472,32$ (mais que 4,5 vezes). Em 2014, os mesmos estados (Pará e Paraná) estão com o menor valor ( $\$$ $1.863,41)$ e o maior valor $(\mathrm{R} \$ 8.749,66)$ dos vencimentos finais de suas carreiras, respectivamente (com a diferença de $\mathrm{R} \$ 6.886,25)$.

$\mathrm{O}$ estado que teve a maior variação absoluta no período foi SP com R $\$$ $4.775,70$ e a menor variação ocorreu no $\mathrm{RN}$, com variação real negativa de $\mathrm{R} \$$ 684,11 . O que significa que os docentes potiguares tiveram rebaixamento do valor do vencimento final de sua carreira docente entre os anos de 2006 e 2014. A maior variação relativa do período apareceu no PI com 239,3\%, enquanto que a menor (negativa) foi a do RN com $-14,6 \%$.

O comportamento da média aritmética dos vencimentos finais é ascendente, pois sai de um valor de $\mathrm{R} \$ 2.920,97 \mathrm{em} 2006$ e passa para um valor de $\mathrm{R} \$ 4.948,55$, estabelecendo uma diferença de $\mathrm{R} \$ 2.217,19$ em termos absolutos e de $69,4 \%$ em termos percentuais.

É interessante observar no gráfico que as linhas de tendência da média e do PSPN novamente não se cruzam. Aliás, afastam-se bastante uma da outra. Isso significa que, como a inclinação da reta do PSPN é sempre a mesma, em geral as redes tenderam a colocar maiores valores de vencimentos nas posições finais das carreiras docentes de suas redes no período, o que não significa que os docentes tenham condições, de fato, de atingirem tais posições.

\section{A DINÂMICA DA REMUNERAÇÃO DOCENTE: UMA LEITURA} A PARTIR DA RAIS

Ao utilizar os microdados da RAIS para estudos sobre a condição do trabalho docente, é importante considerar que a unidade de análise é o vínculo de emprego. Logo, na leitura dos dados desse tópico, é importante saber que as remunerações se referem aos "vínculos de emprego ocupados por professores". Isso é fundamental para a análise da tabela 1, por exemplo, para os casos de professores que tenham dois vínculos na rede estadual ${ }^{7}$. Nesses casos, são contados dois vínculos, embora seja o mesmo sujeito. Isso faz com que o número

\footnotetext{
7

Tal informação pode significar que um professor concursado pode ter dois cargos na carreira ou ainda que se um professor não efetivo entrar e sair da rede mais de uma vez, será contabilizado como um novo vínculo a cada nova entrada.
} 
de vínculos seja maior do que o número de professores (sujeitos). Em 2014, por exemplo, último ano da série histórica apresentada na tabela 1, segundo o Censo da Educação Básica realizado pelo INEP ${ }^{8}$, havia 458,3 mil professores nas 10 redes estaduais analisadas. Todavia, na RAIS do mesmo ano, conforme mostra a tabela 1, foram contados 811,7 mil vínculos de empregos de professores.

A tabela 1 também mostra que a formação típica dos professores das redes estaduais é a formação em nível superior (mais de 85\%). Sabe-se, inclusive, que, em várias redes, é expressivo o número de professores com especialização lato sensu. Porém, a RAIS não capta essa categoria de formação. Os professores com formação em nível médio que representavam quase $20 \%$ no início da série (2006), em 2014 representavam 12,7\%. Esse ponto orientou a decisão de focalizar a análise da remuneração, como será visto nos próximos tópicos, apenas no grupo com formação em nível superior. Por não ser um levantamento específico para professores, a RAIS também não discrimina o tipo de formação em bacharelado ou licenciatura. Quanto ao tipo de vínculo empregatício, a RAIS mostra que a maior parte do quadro de professores das redes estaduais analisadas é composta por estatutários 9 , com proporções abaixo de $60 \%$ no período 2006-2007, acima de $80 \%$ de $2008-2010$ e, de certa forma, estabilizando-se em torno de $72 \%$ no final da série 2011-2014. Quanto ao tempo de emprego, os dados mostram que a distribuição nas categorias propostas (início da carreira $=<5$ anos; meio da carreira $=>5<20$ anos; e final da carreira $>=20$ anos) é bastante assimétrica, uma vez que, em uma estrutura hipotética de carreira com pelo menos 25 anos, seria esperada uma distribuição quase uniforme com $20 \%$ da categoria em cada quinquênio do tempo de emprego (imaginando uma carreira com fluxo regular de ingresso, permanência, aposentadoria e reposição em períodos regulares). A tabela 1, contudo, mostra que durante a série histórica analisada, os professores no início da carreira representaram sempre mais do que $40 \%$ do quadro (certamente, uma análise cruzada com o tipo de vínculo mostraria que grande parte dos iniciantes são os temporários que, por sua condição, não avançam na carreira). Por outro lado, os números mostram que há menos professores no final da carreira (em torno de $15 \%$ ) do que o esperado (20\%). De toda maneira, é importante frisar que cada rede pública do país, devido às particularidades da trajetória histórica das políticas e gestão da educação local, tem características próprias nos aspectos apresentados na tabela 1 .

8 É bom lembrar que a data base de cada ano (após 2007) é o dia 31/5 para o levantamento do Censo da Educação Básica. Portanto, contratações e dispensas após essa data não são computadas.

9 Tal informação, como já dito, deve ser analisada com cuidado, pois algumas redes (por ex. São Paulo) lançaram em alguns anos todos os docentes como estatutários. Além disso, em alguns anos, algumas redes podem ter informado o MT como Funcionários Públicos ou Servidores públicos (de modo genérico) os docentes de suas redes. 
Tabela 1 - Características dos professores das redes estaduais analisadas1, 2006 a 2014

\begin{tabular}{|c|c|c|c|c|c|c|c|c|c|}
\hline \multirow{2}{*}{ Aspecto } & \multicolumn{9}{|c|}{ Ano } \\
\hline & 2006 & 2007 & 2008 & 2009 & 2010 & 2011 & 2012 & 2013 & 2014 \\
\hline Total de professores (n) & 607.831 & 628.339 & 738.317 & 765.196 & 775.860 & 779.861 & 801.277 & 730.700 & 811.759 \\
\hline \multicolumn{10}{|l|}{ Nivel de formaça a $(\%)$} \\
\hline Ensino Fundamental & 3,7 & 4,1 & 1,1 & 0,9 & 0,4 & 0,3 & 0,7 & 0,8 & 0,7 \\
\hline Ensino Médio & 19,5 & 179 & 17,7 & 14,2 & 14,6 & 13,4 & 14,7 & 14,9 & 12,7 \\
\hline Ensino Superior & 76,8 & 779 & 81,2 & 84,8 & 84,7 & 86,0 & 84,2 & 83,3 & 86,2 \\
\hline Mestrado e Doutorado & 0,0 & 0,1 & 0,0 & 0,1 & 0,3 & 0,2 & 0,3 & 1,0 & 0,4 \\
\hline \multicolumn{10}{|l|}{ Tipo de vínculo ( $\%$ ) } \\
\hline Celetista & 5,7 & 1,1 & 1,2 & 1,1 & 1,6 & 1,8 & 1,8 & 1,9 & 1,6 \\
\hline Estatutário & 55,0 & 58,6 & 85,7 & 82,9 & 81,2 & 71,6 & 72,8 & 72,6 & 72,4 \\
\hline Servidor não efetivo + Temporário & 39,4 & 40,3 & 13,2 & 16,0 & 17,3 & 26,6 & 25,4 & 25,6 & 26,0 \\
\hline \multicolumn{10}{|l|}{ Tempo de emprego (\%) } \\
\hline$<5$ anos (inicio da carreira) & 45,7 & 47,9 & 47,5 & 47,4 & 43,1 & 45,3 & 42,1 & 45,3 & 45,6 \\
\hline$>=5<20$ anos & 37,7 & 37,4 & 39,3 & 39,3 & 42,4 & 41,2 & 44,3 & 40,6 & 38,7 \\
\hline$>=20$ anos (final da carreira) & 16,5 & 14,7 & 13,1 & 13,3 & 14,5 & 13,5 & 13,5 & 14,1 & 15,7 \\
\hline
\end{tabular}

Fonte: Elaborado a partir dos microdados da RAIS dos anos de 2006 a 2014

Nota: (1) Redes estaduais dos estados do PA, PI, RN, MT, MS, MG, SP, PR, SC e RS.

A tabela 2 apresenta a remuneração média dos professores com formação em nível superior em três perspectivas: docentes em conjunto; docentes com menos de cinco anos de tempo de emprego; e docentes com pelo menos 20 anos de emprego. Igualmente, apresenta a mediana da remuneração ${ }^{10}$, o coeficiente de variação ${ }^{11}$ e o número de vínculos considerado para compor as médias em cada ano. Assim como a tabela 1, é um esforço de síntese para uma análise geral do conjunto das redes analisadas, embora a remuneração tenha características próprias em cada rede. Isso alerta para a necessidade de se considerar que há grande heterogeneidade na remuneração média (o que é informado pelo coeficiente de variação). A variabilidade ainda é maior porque as médias contemplam as

10 A mediana é uma medida de posição que indica o valor que divide o rol das remunerações analisadas em duas partes com $50 \%$ das observações cada uma.

11 O coeficiente é uma medida de variabilidade calculada pela divisão do desvio-padrão pela média. Valores de até 15\% indica baixa variabilidade. Todavia, não há uma escala padronizada indicando mínimo e máximo para essa medida. 
remunerações de professores estatutários e temporários (vide tabela 1) para dar uma noção da remuneração do quadro geral de professores. Essa separação será realizada nas análises seguintes.

Tabela 2 - Remuneração média dos professores com formação em nível superior, por tempo de trabalho, no conjunto das redes estaduais analisadas1, 2006 a 2014 (valores em R\$ padronizados para uma jornada semanal de 40h e corrigidos pelo INPC para dez/2014)

\begin{tabular}{|c|c|c|c|c|c|c|c|c|c|c|}
\hline $\begin{array}{c}\text { Tempo de } \\
\text { trabalho }\end{array}$ & E statísticas & 2006 & 2007 & 2008 & 2009 & 2010 & 2011 & 2012 & 2013 & 2014 \\
\hline \multirow{4}{*}{$\begin{array}{l}\text { Todos } \\
\text { docentes }\end{array}$} & $\begin{array}{l}\text { Remuneração } \\
\text { média (RS }\end{array}$ & 2.620 & 2.851 & 2.892 & 3.193 & 3.352 & 3.273 & 3.478 & 3.533 & 3.503 \\
\hline & Mediana (RS) & 2.462 & 2.626 & 2.577 & 2.831 & 2.976 & 2.845 & 2.976 & 3.064 & 3.030 \\
\hline & Coef. de variaçâo & $50 \%$ & $54 \%$ & $58 \%$ & $59 \%$ & $59 \%$ & $62 \%$ & $62 \%$ & $62 \%$ & $61 \%$ \\
\hline & número de vinculos & 426.732 & 442.570 & 547.559 & 607.696 & 618.409 & 609.279 & 621.576 & 553.420 & 646.847 \\
\hline \multirow{4}{*}{$\begin{array}{l}\text { Inicio da } \\
\text { carreira } \\
(<5 \text { anos })\end{array}$} & $\begin{array}{l}\text { Remuneração } \\
\text { média (RS }\end{array}$ & 2.184 & 2.455 & 2.330 & 2.653 & 2.744 & 2.518 & 2.495 & 2.488 & 2.487 \\
\hline & Mediana (RS) & 2.057 & 2.280 & 2.154 & 2.186 & 2.372 & 2.192 & 2.279 & 2.299 & 2331 \\
\hline & Coef. de variaçăo & $52 \%$ & $55 \%$ & $56 \%$ & $71 \%$ & $66 \%$ & $70 \%$ & $61 \%$ & $60 \%$ & $55 \%$ \\
\hline & número de vinculos & 185.979 & 200.931 & 243.692 & 263.675 & 251.647 & 250.449 & 237.770 & 227.134 & 276.542 \\
\hline \multirow{4}{*}{$\begin{array}{c}\text { Final da } \\
\text { carreira } \\
(>=20 \text { anos })\end{array}$} & $\begin{array}{l}\text { Remuneração } \\
\text { média (RS }\end{array}$ & 3.411 & 3.829 & 4.062 & 4.086 & 4.198 & 4.080 & 4.541 & 4.649 & 4.826 \\
\hline & Mediana (RS) & 3.139 & 3.446 & 3.635 & 3.622 & 3.617 & 3.608 & 4.050 & 4.197 & 4.400 \\
\hline & Coef. de variaçăo & $52 \%$ & $56 \%$ & $55 \%$ & $52 \%$ & $57 \%$ & $53 \%$ & $48 \%$ & $48 \%$ & $45 \%$ \\
\hline & número de vinculos & 61.353 & 61.821 & 70.913 & 80.385 & 85.334 & 80.887 & 84.404 & 79.666 & 102.682 \\
\hline
\end{tabular}

Fonte: Elaborado a partir dos microdados da RAIS dos anos de 2006 a 2014

Nota: (1) Redes estaduais dos estados do PA, PI, RN, MT, MS, MG, SP, PR, SC e RS.

Inicialmente, da tabela 2 pode-se coligir, de maneira geral, que a remuneração média teve uma evolução em termos reais de 34\% (os valores estão atualizados pelo INPC para dez/2014) no período de 2006 a 2014. Em termos monetários, significa que partiu de R 2.620 (3,6 salários mínimos) em 2006 e chegou em $\mathrm{R} \$ 3.505$ (4,8 salários mínimos) no final da série. Todavia, nota-se que a evolução não se deu em mesma intensidade em todo o período. De 2006 a 2009 houve um aumento de $22 \%$ e de 2009 a 2014 de apenas 10\%. A média da remuneração dos professores com menos de cinco anos de serviço (ou no início da carreira) se deu de maneira diversa em relação ao conjunto (é importante frisar que está nesse bojo, em geral, quase a totalidade dos professores temporários das redes). No período, as médias relativas ao início da carreira foram de 17\% a 29\% inferiores às médias do conjunto dos professores. Isso mostra que há amplitude nas remunerações no interior das redes em decorrência dos planos de carreira e das tabelas de vencimentos (conforme apresentado na seção 3). Porém, a remuneração média do início da carreira teve crescimento real de $14 \%$, sendo que 
de 2006 a 2009 cresceu $21 \%$ e de 2009 a 2014 diminui em 6\%. Ou seja, no período de vigência plena do Fundeb e a partir do primeiro ano de vigência do PSPN, houve redução na remuneração média dos professores, se analisadas as 10 redes estaduais conjuntamente. Em melhor situação estavam os professores do final da carreira. O crescimento real da média no período foi de 41\%. De 2006 a 2009 o crescimento foi de $20 \%$ e de 2009 a 2014 foi de $18 \%$. Ou seja, quase manteve o ritmo de crescimento anterior. A amplitude em relação à média dos professores no início de carreira aumentou consideravelmente. Em 2006, a remuneração média de $\mathrm{R} \$ 3.411$ representava 4,7 salários mínimos e a distância em relação ao início da carreira era de 56\%. Em 2014, a média de $\mathrm{R} \$ 4.826$ representava 6,7 salários mínimos e a distância aumentou para 94\%. As três linhas do gráfico 4 , ilustram os fenômenos revelados na tabela 2 .

\section{Gráfico 4 - Remuneração média dos professores com formação em nível superior, por tempo de trabalho, no conjunto das redes estaduais analisadas1, 2006 a 2014 (valores em R \$ padronizados uma jornada semanal de 40h e corrigidos pelo INPC para dez/2014)}

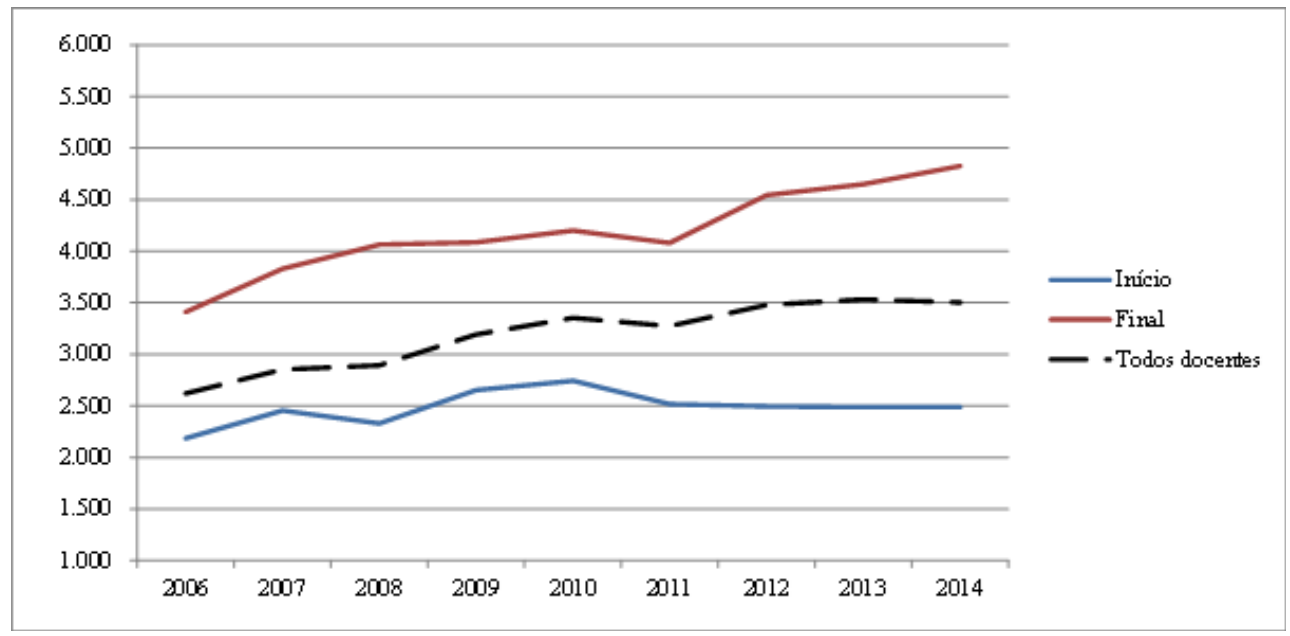

Fonte: Elaboração a partir dos microdados da RAIS dos anos de 2006 a 2014

Nota: (1) Redes estaduais dos estados do PA, PI, RN, MT, MS, MG, SP, PR, SC e RS.

Embora seja discutível qual seria uma amplitude "ideal ou aceitável” entre a remuneração inicial e final para manter a atratividade da carreira, os números da tabela 2 representados no gráfico 4 revelam um quadro preocupante se analisados em perspectiva com os números da tabela 1 , que mostram que os docentes não têm chegado ao final da carreira em proporções esperadas. Ou seja, paga-se mais no final da carreira para um pequeno contingente que consegue chegar a mais 
de 20 anos de trabalho (em torno de 15\%, segundo a tabela 1). Novamente, os números das 10 redes em conjunto, revelam a importância de replicar essa análise para cada rede a fim de captar os traços da política local que podem ser bastante diversos.

O gráfico 5 propõe uma continuidade dessa análise mostrando os dados por rede estadual. Porém, focaliza a remuneração dos professores estatutários (que correspondem a $75 \%$ do quadro, segundo a tabela 1). O objetivo desse gráfico é revelar a dinâmica da remuneração do quadro estável da rede que está sob a política remuneratória da rede expressa nos planos de carreira e tabelas de vencimento.

\section{Gráfico 5 - Remuneração média dos professores estatutários com formação em nível superior, por rede estadual, 2006 a 2014 (valores em R\$ padronizados uma jornada semanal de 40h e corrigidos para dez/2014)}

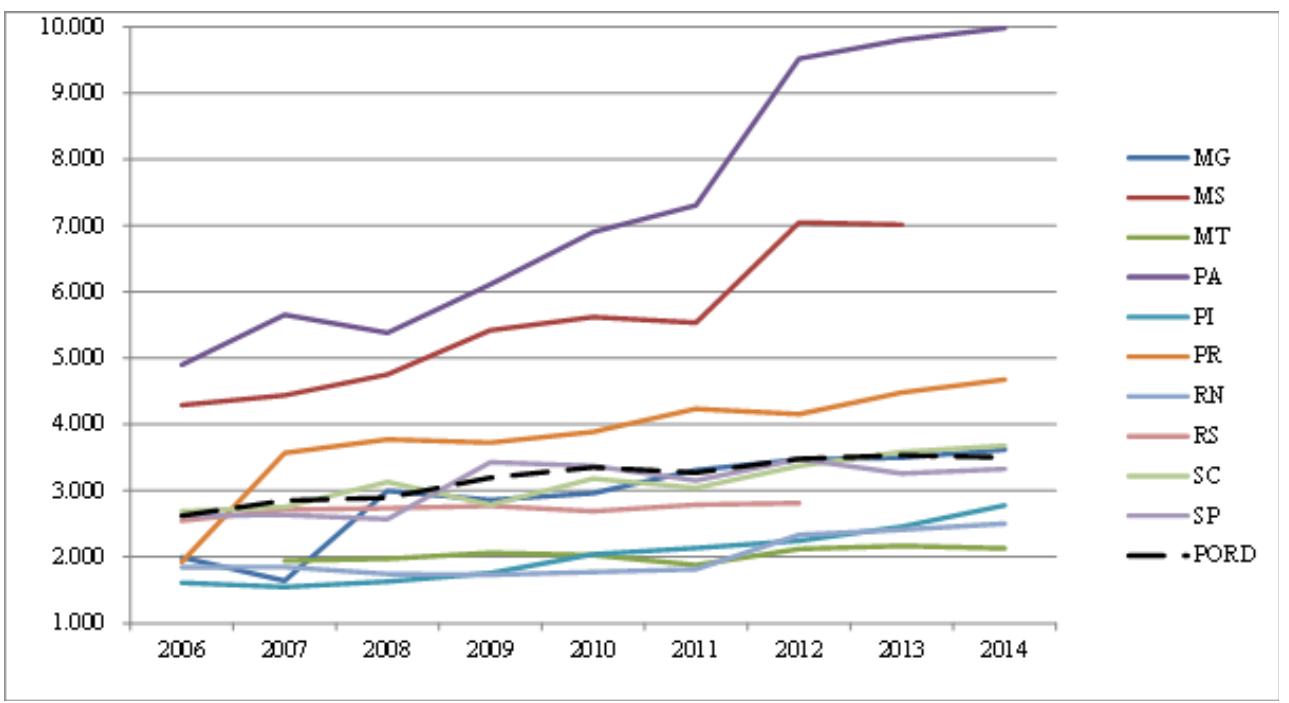

Fonte: Elaborado a partir dos microdados da RAIS dos anos de 2006 a 2014

Depreende-se do gráfico 5, a diversidade das condições remuneratórias a que estão submetidos os professores efetivos nas 10 redes analisadas. A dinâmica no período 2009 a 2014 (para focalizar o período PSPN e do Fundeb pleno) é também bastante diversa. Se, no geral, o crescimento real das remunerações no conjunto das 10 redes foi de 9,7\% no período 2009-2014, no Pará foi de 63,4\% , seguido pelo Piaú (58,2\%), Rio Grande do Norte (44,7\%), Santa Catarina (32,2\%), Mato Grosso do Sul (29,4\%), Minas Gerais (26,5\%), Paraná (25,6\%) e Rio Grande do Sul (14,4\%). Ficaram abaixo da média do conjunto das redes, Mato 
Grosso (3,2\%) e São Paulo (-3,0\%). A dinâmica nesse período resultou em um quadro quanto à média remuneratória (considerando a padronização para uma jornada de 40 horas semanais) em 2014, que coloca o Pará na melhor situação (com média de $\mathrm{R}$ \$ 9.986), seguida do Mato Grosso do Sul $(\mathrm{R} \$ 7.013)^{12}$ e Paraná $(\mathrm{R} \$ 4.679)^{13}$. Seguindo a ordem, quatro estados apresentam médias entre $\mathrm{R} \$ 3 \mathrm{mil}$ e R $\$ 4$ mil (Santa Catarina= R \$ 3.681; Minas Gerais=R \$ 3.619; e São Paulo R $\$$ 3.328; e Rio Grande do Sul=R \$3.169). É esse grupo que está mais próximo da média do conjunto das 10 redes analisadas $(\mathrm{R} \$ 3.505)$. As piores médias foram verificadas no Piauí ( $\mathrm{R} \$ 2.777)$, Rio Grande do Norte ( $\mathrm{R} \$ 2.502)$ e Mato Grosso $(\mathrm{R} \$ 2.127)$.

No gráfico 6, é possível perceber a dinâmica dos valores do PSPN da média do gasto-aluno-ano do Fundeb ${ }^{14}$ nos dez estados, os vencimentos médios iniciais para docentes com nível superior e os vencimentos médios finais das carreiras das dez redes estaduais; bem como os valores médios das remunerações de docentes estatutários com formação em nível superior em início de carreira e com mais de vinte anos (final da carreira).

13 É importante considerar que no PA, MS e PR a jornada padrão dos professores é de 20 horas semanais. Ou seja, os valores das médias apresentados não são, de fato, encontrados nos holerites dos professores, uma vez que são oriundas da padronização para 40 horas.

14 O gasto-aluno do Fundeb foi apurado a partir dos valores das despesas realizadas com os recursos do Fundeb no âmbito dos estados e dividido pelo total de matrículas da Educação Básica em cada ano da série analisada. A fonte relativa às despesas do Fundeb foi o Sistema de Informações sobre Orçamentos Públicos em Educação (SIOPE) do Fundo Nacional de Desenvolvimento da Educação (FNDE). 


\section{Gráfico 6 - Vencimentos e Remuneração média dos professores estatutários com formação em nível superior das redes estaduais}

analisadas1e valores do Fundeb e PSPN, 2006 a 2014 (valores em R\$ padronizados uma jornada semanal de $40 \mathrm{~h}$ e corrigidos pelo INPC para $\operatorname{dez} / 2014)$

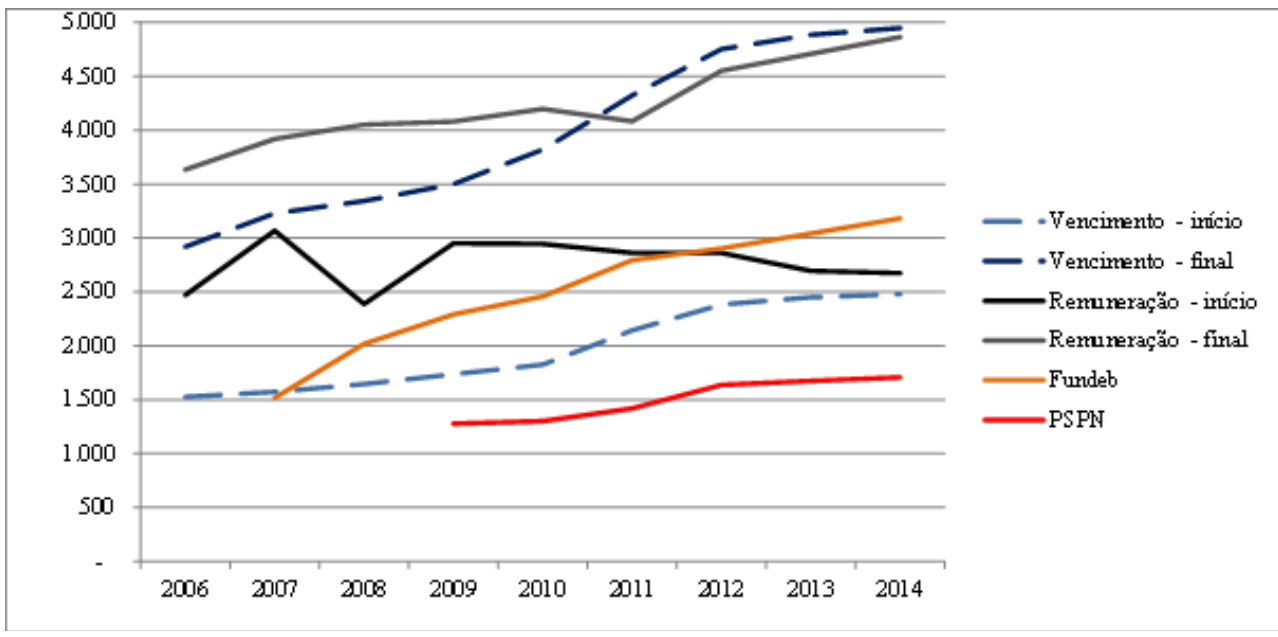

Fonte: Elaborado a partir dos microdados da RAIS dos anos de 2006 a 2014

Nota: (1) Redes estaduais dos estados do PA, PI, RN, MT, MS, MG, SP, PR, SC e RS.

Percebe-se que os valores do PSPN variaram de 2009 a 2014 em 33,5\%, pois saíram de $R \$ 1.280$ e atingiram o valor de $R \$ 1.710$. O gasto-aluno-ano do Fundeb saiu de R \$ 1.519 em 2007 e foi para R\$ 3.184 em 2014, o que significou uma variação de 109,6\% no período e de 39\% entre 2009 e 2014. Chama atenção a curva que vai separando os dois valores no gráfico 6 (Fundeb e PSPN) e estabelece uma diferença de valores de R \$ 1.010 em 2009 e de R $\$ 1.474$ em 2014.

Quanto aos vencimentos médios iniciais, eles partem de $\mathrm{R} \$ 1.527 \mathrm{em}$ 2006 e alcançam R 2.480 em 2014 (uma diferença percentual de 62,4\%). Após 2009, o valor percentual foi de 42,7\%. Os vencimentos médios finais partem de R \$ 2.920 em 2006 e alcançam R \$ 4.948 em 2014 (com variação percentual de $67,3 \%$ no período). Importante destacar que a diferença entre os vencimentos médios iniciais e finais aumentam na série histórica, pois a diferença foi de $\mathrm{R} \$$ 1.394 em 2006 e de R\$2.468 em 2014.

Quando verificamos o comportamento da remuneração média inicial dos professores estatutários com formação de nível superior (com menos de cinco anos na carreira), percebemos que ela parte de $\mathrm{R} \$ 2.471 \mathrm{em} 2006$ e atinge $\mathrm{R} \$$ 2.676 com somente $8,3 \%$ de ganho real no período, mas negativa $(-9,3 \%)$, se tomarmos de 2009 a 2014. Quanto à remuneração média do final da carreira (mais 
que 20 anos de carreira), ela parte de $R$ \$ 3.638 em 2006 e alcança $R \$ 4.864$ em 2014, com uma variação percentual de $33,6 \%$ no período total e de $19,2 \%$ depois da implantação do PSPN. A diferença entre as médias iniciais em 2006 foi de R\$ $1.163(43,5 \%)$ e a diferença entre as remunerações médias finais em 2014 foi de $\mathrm{R} \$ 2.188(81,8 \%)$ em 2014.

No entanto, o que chama atenção no gráfico 6 são as relações entre as remunerações médias iniciais e os vencimentos médios iniciais e, principalmente, entre as remunerações médias finais e os vencimentos médios finais. O gráfico 6 indica uma aproximação dos valores das remunerações médias iniciais com os vencimentos iniciais: se em 2006 a diferença entre eles era de $\mathrm{R} \$ 945$ (em termos percentuais, $61,9 \%$ ), a partir do PSPN foi diminuindo e passou a ser somente de $\mathrm{R} \$ 195 \mathrm{em} 2014$ (o que indicou uma diferença percentual de somente 7,9\%). Isso pode indicar que os estados que praticavam pagamentos por meio de gratificações, prêmios ou adicionais, a partir do PSPN começaram a incorporar tais valores aos vencimentos, fazendo com que diminuísse a diferença entre o que estava definido para o valor do vencimento inicial e a remuneração paga aos docentes. Destacamse também as diferenças entre as remunerações médias finais e os vencimentos médios finais na série histórica. Era esperado que o valor da remuneração fosse a somatória dos vencimentos com os demais itens de composição da remuneração, o que levaria a valores sempre maiores que os vencimentos. Mas, se em 2006 esta diferença foi de $\mathrm{R} \$ 714$, correspondendo a $24,4 \%$ (com as incorporações descritas anteriormente), correspondendo a essa interpretação, em 2011 esta diferença se inverte, pois em 2014 a diferença passou a ser negativa (- R \$ 239 em 2011 e -R \$ 87 em 2014), o que correspondeu a uma diferença negativa de -1,7\% em 2014. Tal fenômeno pode indicar que os docentes com mais de 20 anos de carreira (ao seu final) não estão, de fato, atingindo os valores dos vencimentos finais das carreiras. Ou seja, as administrações podem até colocar os valores de vencimentos finais mais altos em sua legislação (talvez como um "chamariz" para os docentes permanecerem em suas redes), mas que estabelecem "travas" para permitir esse atingimento e realizar os pagamentos (como explicitar que para atingir tal condição e realizar o pagamento deveriam ter "condições orçamentárias" ou os docentes deveriam ter títulos "inalcançáveis" como o pós-doutoramento ou outra razão) e, efetivamente, não permitem que a maioria dos docentes alcancem as últimas posições e não pagam as devidas remunerações finais aos docentes. 


\section{CONSIDERAÇÕES FINAIS}

Os dados analisados mostraram evidências de que no período analisado (de 2006 a 2014), coincidente com a transição do Fundef para o Fundeb e do início da vigência do PSPN, houve crescimento real na remuneração média dos professores das 10 redes estaduais analisadas, apesar de bastante variável entre as redes (de $10 \%$ a 143\%). No período 2009-2014, o crescimento foi menos expressivo (variou de 3\% a $63 \%$ nas redes analisadas) e negativo (-3\%) em São Paulo.

Assim, é razoável imaginar que o Fundeb foi um dos fatores que possivelmente contribuiu para o crescimento da remuneração média dos professores devido à nova lógica de financiamento para todas as etapas e modalidades da Educação Básica trazida pelo fundo (as redes estaduais não contavam com recursos para o financiamento do ensino médio no período do Fundef).

Outros achados relevantes se referem à pequena proporção dos professores que atingem o final da carreira e que, portanto, recebem as maiores remunerações reservadas aos que permanecem por mais de 20 anos na rede. Igualmente, na análise dos dados de vencimentos e remuneração, verificou-se que a média dos vencimentos finais é superior à média das remunerações, o que é um contrassenso conceitual e revela que os vencimentos finais podem não estar sendo pagos (por exigências inalcançáveis) ou são pagos a apenas uma quantidade muito pequena de docentes.

A possível contribuição das análises propostas neste artigo é revelar (ainda mais) como a remuneração docente tem contornos muito particulares em cada rede e, ao mesmo tempo, apesar das limitações e riscos, a importância de análises conjuntas para se compreenderem as diferenças e se discutir até que ponto elas são aceitáveis ou não no âmbito de uma federação. Outra possível contribuição seria instigar o monitoramento das políticas de remuneração em séries históricas longas em âmbito local por meio da replicação de tabelas e gráficos apresentados.

A pesquisa nacional da qual este artigo reporta parte dos resultados permitiu a análise das diferentes fontes de dados que contêm informações sobre a remuneração dos professores (PNAD, RAIS, Folhas de pagamentos e Tabelas de vencimentos). Assim, foi possível conhecer os limites e as potencialidades de cada uma. Nesse ponto, certamente, os microdados da folha de pagamento são a fonte mais fidedigna para análise da remuneração docente. A partir deles é possível compreender a composição da remuneração de cada professor em sua rede de atuação considerando-se vários detalhes e características funcionais de cada docente. Porém, apesar de se tratar de dados públicos (inclusive pode-se consultar 
a remuneração dos professores nominalmente nos portais da transparência) e de se tratar de dados de despesas pagas com dinheiro público, os governos, em geral, não permitem acesso aos microdados. Nesse aspecto, a interpretação dos governos quanto a dar transparência ao valor das remunerações dos servidores públicos se restringe a explicitar a condição de cada servidor individualmente e não à explicitação de como a administração gastou os recursos destinados à folha de pagamento. Obstáculos de diferentes naturezas são colocados como forma de negativa de acesso a esses dado, em plena vigência da Lei de Transparência - Lei Complementar 131/2009 (BRASIL, 2009). Todavia, cada folha de pagamento revela informações de apenas uma rede. Tratá-las de modo a permitir comparações entre redes não seria uma tarefa simples. Nesse ponto, a RAIS é uma fonte muito valiosa, por se tratar de um levantamento em âmbito nacional. No quesito comparação entre redes, a RAIS supera a folha de pagamento em vantagens comparativas (ainda que não capte vários detalhes que só são possíveis nas folhas).

Finalizando, este estudo reforça a importância da pesquisa sobre remuneração dos docentes das escolas públicas com a participação em rede de pesquisadores de diversos estados para compreender a heterogeneidade da situação dos professores no contexto de uma federação tão diversa. Diante da complexidade, relevância e abrangência do tema, é basilar a formação de novos pesquisadores (da iniciação científica ao doutorado) e também a troca de perspectivas analíticas e metodológicas entre pesquisadores experientes para potencializar novos estudos. Isso requer, igualmente, financiamento de maior vulto.

Nesse sentido, é razoável pensar na estruturação de um observatório nacional permanente para acompanhar a dinâmica da situação remuneratória dos professores nos diferentes estados e municípios para dar conta da complexidade do tema em um país cuja carreira docente é fragmentada em quase 5.600 redes públicas de ensino (Federal, Distrito Federal, 26 redes estaduais e 5.570 municipais) com autonomia para legislar. Daí a importância de leis como a do Fundeb e do PSPN para estabelecerem parâmetros nacionais mínimos para pautar as políticas subnacionais.

\section{REFERÊNCIAS}

ARELARO, L. R. Financiamento e qualidade da educação brasileira: algumas reflexões sobre o documento "Balanço do primeiro ano do Fundef - relatório MEC”. In: DOURADO, L. F. Financiamento da educação básica. Campinas, SP: Autores Associados; Goiânia,GO: Editora da UFG, 1999. 
BASSI, M.; Ednir, M.. Bicho de Sete cabeças - Para entender o financiamento da educação brasileira. São Paulo: Ação Educativa, Fundação Peirópolis. 2009.

BRASIL, MEC, INEP. Nota Técnica $\mathrm{n}^{\mathbf{0}}$ 10/2017/CGCQTI/DEE. A remuneração média dos docentes em exercício na educação básica: pareamento das bases de dados do Censo da Educação Básica da RAIS, Brasília: INEP, 2017

BRASIL, MINISTÉRIO DO TRABALHO (MTb). Manual de Orientação da Relação Anual de Informações Sociais (RAIS): ano-base 2016. Brasília: MTb, SPPE, DES, CGET, 2016. 49p.

BRASIL. Lei Complementar $\mathbf{n}^{\circ}$ 131, de 27 de maio de 2009. Acrescenta dispositivos à Lei Complementar $n^{\circ} 101$, de 4 de maio de 2000, que estabelece normas de finanças públicas voltadas para a responsabilidade na gestão fiscal e dá outras providências, a fim de determinar a disponibilização, em tempo real, de informações pormenorizadas sobre a execução orçamentária e financeira da União, dos Estados, do Distrito Federal e dos Municípios. Disponível em http:/ / www.planalto.gov.br/ccivil_03/LEIS/LCP/Lcp131.htm

BRASIL. Lei No 11.738, de 16 de julho de 2008. Regulamenta a alínea "e" do inciso III do caput do art. 60 do Ato das Disposições Constitucionais Transitórias, para instituir o piso salarial profissional nacional para os profissionais do magistério público da educação básica. Disponível em http://www.planalto.gov. br/ccivil_03/_ato2007-2010/2008/lei/111738.htm

BRASIL. Lei n. 11.494, 2007. Regulamenta o Fundo de Manutenção e Desenvolvimento da Educação Básica e de Valorização dos Profissionais da Educação - FUNDEB, de que trata o art. 60 do Ato das Disposições Constitucionais Transitórias; e dá outras providências. Brasil: Casa Civil, 2007.

BRASIL. Emenda Constitucional $n^{\circ}$ 53, de 19 de dezembro de 2006. Dá nova redação aos arts. $7^{\circ}, 23,30,206,208,211$ e 212 da Constituição Federal e ao art. 60 do Ato das Disposições Constitucionais Transitórias. Disponível em: <http://www.planalto.gov.br/ccivil_03/constituicao/emendas/emc/emc53. htm>. Acessado em: 14/04/2018.

BRASIL, MEC, INEP. Nota Técnica $n^{\mathbf{0}}$ 10/2017/CGCQTI/DEE. A remuneração média dos docentes em exercício na educação básica: pareamento das bases de dados do Censo da Educação Básica da RAIS. 
BRASIL. Lei n. 9.424, 1996. Dispõe sobre o Fundo de Manutenção e Desenvolvimento do Ensino Fundamental e de Valorização do Magistério, na forma prevista no art. $60, \int 7^{\circ}$, do Ato das Disposições Constitucionais Transitórias, e dá outras providências. Brasil: Casa Civil, 1996.

BRASIL. Constituição da República Federativa do Brasil (1988). Brasília, DF: Senado Federal, 1988. Disponível em: <http://www.senado.leg.br/atividade/ const/con1988/CON1988_05.10.1988/ art_7_.asp>. Acesso em: 22 mar. 2012.

CASTRO, J. A. Financiamento e gasto público na educação básica no Brasil: 19952005. in Educação Escolar: os desafios da qualidade. Educação e Sociedade: Revista de Ciência da Educação. Centro de estudos de Educação e Sociedade. Campinas : CEDES, v. 28, n. 100 - Especial. p.641-1274,Out. 2007.

DAVIES, N. O FUNDEF e o Orçamento da Educação: Desvendando a Caixa Preta. Niterói : Davies Nicholas. (1998).

FARENZENA, N.. A política de financiamento da educação básica: rumos da legislação brasileira. 1. ${ }^{a}$ ed. Porto Alegre, RS: UFRGS, 2006.

FERNANDES, M. D. E.; GOUVEIA, A. B.; BENINI, E. G. Remuneração de professores no Brasil: um olhar a partir da Relação Anual de Informações Sociais (RAIS). Educ. Pesqui., v. 38, n. 2, p.339-356, 2012.

GOUVEIA, A.B.; CRUZ, R.E.; CAMARGO, R.B.; OLIVEIRA, J. Condições de trabalho docente, ensino de qualidade e custo-aluno ano. Revista Brasileira de Política e Administração da Educação, v. 22, p. 253-276, 2006.

JACOMINI, M. A.; ALVES, T.; CAMARGO, R.B. Remuneração docente: desafios para o monitoramento da valorização dos professores brasileiros no contexto da Meta 17 do Plano Nacional de Educação. Archivos Analíticos de Políticas Educativas / Education Policy Analysis Archives, v. 24, p. 1-35, 2016.

OLIVEIRA, R. P. de. O financiamento da educação. In: OLIVEIRA, R. P. de; ADRIÃO, T. Gestão, financiamento e direito à educação: análise da Constituição Federal e da LDB. 3. ed. São Paulo: Xamã, 2007.

PINTO, J. M. R. Os recursos para a educação no Brasil no contexto das finanças públicas. Brasília: Editora Plano, 2000. 
PINTO, J. M. R.. A política recente de fundos para o financiamento da educação e seus efeitos no pacto federativo. in Educação Escolar: os desafios da qualidade. Educação e Sociedade: Revista de Ciência da Educação. Centro de estudos de Educação e Sociedade. Campinas : CEDES, v. 28, n. 100 - Especial. Out. 2007. p.641-1274.

PORD. Referências bibliográficas. São Paulo: PORD. 2013, mimeo.

RUBENS BARBOSA DE CAMARGO é Doutor em Educação (FE/USP), Professor do Departamento de Administração Escolar e Economia da Educação, Faculdade de Educação da Universidade de São Paulo. E-mail: rubensbc@usp.br

THIAGO ALVES é Doutor em Administração (FEA/USP), Professor do Departamento de Planejamento e Administração Escolar e do Programa de PósGraduação da Universidade Federal do Paraná. E-mail: thiagoalves.edu@gmail. com

MARIA DA GRAÇA BOLLMANN é Doutora em Educação (PUC/RJ) e pósdoutora em Educação Superior (UL-Lisboa), Professora do Programa de PósGraduação em Educação da Universidade do Sul de Santa Catarina (Unisul). E-mail: graca.bollmann@unisul.br

Recebido em maio de 2018

Aprovado em julho de 2018 